\title{
A CRŔTICA LITERÁRIA \\ E O ENSINO DA LITERATURA NA ERA DIGITAL
}

http://dx.doi.org/10.11606/issn.2237-1184.v0i24p125-135

Mirhiane Mendes de Abreu

Universidade Federal de São Paulo (Unifesp)

\section{RESUMO}

Este artigo tem como objetivo debater, a partir do ensino da literatura, o consumo e o valor da interatividade digital e da crítica literária nas transformações por que passa a leitura. Para isso, foi proposto um paralelo entre o papel da crítica literária e os fenômenos do ciberespaço, a fim de examinar o ato crítico como ingrediente essencial na dinâmica da leitura e seu lugar na escola.

ABSTRACT

This article aims to discuss, from the teaching of literature, the consumption and value of digital interactivity and literary criticism in the transformations through which reading happens. Then, a parallel was proposed between the role of literary criticism and the phenomena of cyberspace in order to examine the critical act as an essential ingredient in the reading dynamics and its place in school.
PALAVRAS-CHAVE

Ensino de literatura. Crítica literária. Interatividade digital. Leituras.

\section{KEYWORDS}

Literature teaching. Literary critique.

Digital interactivity. Readings. 


\section{- Considerações iniciais}

As categorias leitor, leitura e contemporaneidade expressam conceitos relevantes para a crítica e para a teoria literária. Observadas em conjunto, trazem à luz duas situações. A primeira delas refere-se à integração do leitor ao ambiente de ensino formal, isto é, a escola; a segunda diz respeito à consideração da literatura nos vários campos da cultura, incluindo os meios de comunicação (desde os jornais e as revistas até as redes sociais, blogs e afins). Assim sendo, considero importante afirmar que pensar leitores e leituras na contemporaneidade é examinar, simultaneamente, o ensino da literatura na escola básica e a crítica literária como atividade universitária. Nos dois casos, significa também examinar o cruzamento entre essas instâncias de produção e disseminação do conhecimento e outros materiais de expressão cultural, notadamente os meios digitais.

A literatura, como objeto, é interpretada por um eixo de referência, ou seja, um texto é compreendido a partir da inclinação do leitor para determinadas perspectivas críticas. Para isso, a leitura articula termos e conceitos (por exemplo, influência, intertexto, paródia, ruptura, dentre outros), explicitados ou não, com os quais o discurso crítico lida para erigir ou problematizar cânones e apontar valores das obras atuais. Ao mesmo tempo, leitor, leitura e contemporaneidade são termos que carregam consigo outros elementos concernentes à teoria literária, notadamente a relação entre literatura e sociedade e a formação do leitor. A esse respeito, veja-se o trecho de uma reflexão desenhada por João Alexandre Barbosa, em "Literatura e sociedade do fim do século":

Mas a insistência nas categorias de leitura e leitor que vai dominando as minhas reflexões não pode e não deve ser escamoteada: pelo contrário, ela é reveladora de uma atitude com relação ao texto literário que encontra o seu respaldo nas próprias transformações que vêm sofrendo os modos de articulação entre experiência, representação e linguagem, que são, por sua vez, os vetores principais das relações entre literatura e sociedade."1

Dizendo de outro modo e secundando a perspectiva acima, os elementos que urdem o tecido contemporâneo em sua relação com a

${ }^{1}$ BARBOSA, João Alexandre. BARBOSA, João Alexandre. "Literatura e sociedade do fim do século". In: Alguma crítica. Cotia: Ateliê Editorial, 2002, p. 16. 
literatura são articulados por uma trama composta por três itens experiência, representação e linguagem - e tais componentes são, por sua vez, os vetores da ligação entre literatura e sociedade, seus limites e seus alcances. No interior da linguagem literária, portanto, são verificadas as mudanças processadas na ordem cultural, as quais exigem das formas de transmissão e consumo um exame mais contundente, não como artifício retórico, mas como reflexão sistematizada sobre o cotidiano cultural, de que a literatura e a escola são partícipes.

Leitura é uma prática cultural imediata da aprendizagem escolar. Podemos reconhecer duas formas específicas de ler: a acadêmica e a dos leitores não profissionais. De maneiras diferentes, ambas estão ou estiveram inteiradas ao ambiente de ensino e ao universo tecnológico; uma e outra instituem e incidem sobre a escrita, a codificação da linguagem e a oferta de protocolos de leitura. É preciso observar, contudo, que o percurso da leitura de uma obra literária efetua-se por paradigmas e esta é uma prática que argumenta em favor de que o ensino da literatura não dispensa os protocolos ofertados pelo discurso crítico e não deveria, da mesma forma, isolar as figurações da leitura no mundo digital.

\section{Uma questão central: a crítica literária e o ensino da literatura}

Apesar de todo o discurso sobre a crise, o caos e o fim da literatura, o ensino da literatura e a crítica literária são objeto de diversos meios de elocução reflexiva. Meu interesse sobre a questão é específico: compreender as formas de leitura no tempo presente e, para isso, a escolha teórico-metodológica é evidenciar o leitor nesse processo, não atribuindo hierarquia entre o leitor especializado (o crítico) e o comum. É preciso, de antemão, enunciar que a leitura literária e a formação de leitores, se possuem um componente familiar essencial, formalizam-se na escola. Isto equivale a dizer que a construção do leitor ocorre, regularmente, no ambiente de ensino formal, condição que nos leva a considerar o professor e seu lugar central na produção dos atos de leitura.

Uma das tarefas mais difíceis para o professor de literatura é delimitar o campo que irá contemplar e fazer operar nele suas atitudes e seu entusiasmo como leitor. Além disso, não obstante tantas reflexões teóricas, sabemos, entretanto, que aquilo que se processa no cotidiano escolar acaba por simplesmente rotinizar o conhecimento de instrumentais de síntese histórica e/ou teórica, que se dão em observância a elementos os mais variados, muitas vezes em prejuízo do texto em si. Um breve resumo desses instrumentais nos mostra o seguinte cenário: 1) de um lado, há um rastreamento histórico (ainda que da história literária), pronunciando no ensino da literatura os fundamentos conceituais de movimentos estéticos e, no caso brasileiro, uma remodelação da perspectiva nacionalista da crítica de raiz romântico-naturalista; 2) de 
outro, o trabalho admite o desprestígio da história literária e absolutiza questões teóricas, mas reduz, igualmente, a experiência literária como objeto de leitura; e 3) estudos temáticos de questões coletivas e agendas sociais.

A meu ver, tanto uma abordagem externa (histórica ou ideológica), quanto uma abordagem puramente cerrada no texto não criam condições minimamente empáticas para que mova alguém a ler obras literárias depois de concluídos os anos escolares. Afinal, embora o conjunto de algumas noções seja requestado na trajetória escolar de qualquer indivíduo, a literatura compartilha um conjunto mais amplo da atividade cultural e da produção do belo. É preciso insistir nisso para ampliar o alcance do ensino da literatura na contemporaneidade e o trabalho do professor da Escola Básica. Isto porque o professor de literatura, diferentemente dos docentes de outras disciplinas, lida com o Belo e seu objeto envolve, ao mesmo tempo, memória, tradição, conhecimento, sensibilidade e subjetividade. Dentro dessas condições, as categorias leitor, leitura, linguagem e representação são colocadas diante das tensões constitutivas do texto literário, ainda que esse objeto seja assimilado como organismo institucional de matéria escolar.

Essa vivacidade do texto pode bem ser percebida a partir das considerações formuladas por Johan Huizinga, em Homo ludens:

Poesis doctrinae tanquam somnium - a poesia é como um sonho de amor filosófico, segundo a profunda definição de Francis Bacon. [...]

A primeira coisa que é preciso fazer para ter acesso a essa compreensão é rejeitar a ideia de que a poesia possui apenas uma função estética ou só pode ser explicada através da estética. Em qualquer civilização viva e florescente, sobretudo nas culturas arcaicas, a poesia desempenha uma função vital que é social e litúrgica ao mesmo tempo. ${ }^{2}$

Ao tratar o problema do jogo como função da cultura e a poesia aqui apreendida em sentido amplo - como efeito direto dessa função, Huizinga deixa de lado fatores quantitativos que possam presidir a atividade literária e situa o tema pela função lúdica da poiesis. Essa função - escreve o filósofo, prosseguindo - "se exerce no interior da região lúdica do espirito, no qual as coisas possuem uma fisionomia inteiramente diferente da que apresentam na "vida comum", e estão ligadas por relações diferentes das da lógica e da causalidade"3. A literatura está para além dessas metodologias ou perspectivas moralizantes e se exprime, privilegiando a individualidade, como um produto mais requintado no campo do saber, porque amplia nossas experiências e nos incita a imaginar outras maneiras de conceber e organizar o mundo. Não me parece incompatível que o

\footnotetext{
${ }^{2}$ HUIZINGA, Johan. "O jogo e a poesia". In: __. Homo ludens: o jogo como elemento da cultura. São Paulo: Perspectiva, 2010, p. 134.

3 Ibidem, p. 135
}

128 | D O S S I Ê : LEITORES E LEITURAS NA CONTEMPORANEIDADE 
ensino da literatura revolva a riqueza de significados que o texto contém, aceite o desafio, especialmente no Ensino Médio, de alcançar a experiência lúdica da leitura e desperte o conhecimento assimilado ao longo do tempo.

O que emerge aqui é uma duplicidade: a leitura é um prazer desinteressado e, ao mesmo tempo, um bem imaterial constituído por uma série de funções. Algumas delas foram elencadas por Umberto Eco, em "Sobre as funções da literatura" ${ }^{4}$, tais como: a capacidade de manter o exercício da língua como patrimônio coletivo, criar identidade e comunidade e, por fim, educar. Essa educação, no meu ponto de vista, tem seu efeito se proceder de uma relação entre critérios de textualidade e auto-referencialidade poética e as práticas culturais que fazm circular esse texto. Ao mesmo tempo, se há subjetividade do indivíduo leitor e múltiplos planos de interpretação, eles não se resumem aos juízos puramente subjetivos do aluno e estão submetidos a um "exercício de fidelidade e de respeito na liberdade da interpretação"s, que dizem respeito ao que é proporcionado pela escola e pelo professor, isto é, referem-se a um trabalho de formação de conhecimento.

Desse modo, se tomarmos como fulcro reflexivo sobre o ensino da literatura os temas teóricos conceituais e os modos pelos quais o poético se expande, nós nos dirigimos para outra dinâmica de leitura, que é a crítica literária.

Ainda que o solo da crítica seja movediço, está claro que tratar criticamente um objeto é fazer um gesto de escolha não somente sobre o campo do presente, mas principalmente sobre o campo da cultura. É também fazer convergir para o contemporâneo as estruturas históricas da representação literária. $\mathrm{O}$ desejo de intervir no presente e agir sobre a cultura é indissociável do ato crítico em literatura, uma vez que este ato se não se resigna a ser apenas refém do marketing das editoras e autores ou de grupos - é sempre, além de um desejo de conhecimento de um objeto particular, uma eleição e uma declaração convicta sobre sua permanência no curso da tradição literária. Mesmo quando se apresenta como pura afirmação de gosto, o ato crítico se insere na cultura e incide sobre a escola porque tem em vista a direção do futuro, por meio da afirmação ou da recusa do que deve ou não deve ser valorizado, do que merece ou não continuidade. Dessa perspectiva, o ato crítico é, ainda que se queira apenas um ato de compreensão ou avaliação, um gesto de eleição. Destacar como digno de atenção crítica um texto em meio à miríade de textos que se oferecem significa reconhecer sua importância ou seu poder.

Dentro dessa perspectiva conceitual e funcional sobre crítica literária, o crítico constitui-se como um leitor que produz um discurso erudito sobre determinada obra ou um conjunto de obras, quer sejam elas

\footnotetext{
${ }^{4}$ ECO, Umberto. "Sobre as funções da literatura". In: 21. Sobre a literatura. Rio de Janeiro: Record, 2003, p. 9${ }^{5}$ Ibidem, p. 12.
}

129 | D O S S I E : LEITORES E LEITURAS NA CONTEMPORANEIDADE 
contemporâneas a ele, quer não. Trata-se de um leitor seletivo que elucida modelos e efeitos do texto e propõe paradigmas interpretativos que serão revisitados pelo ensino da literatura.

A experiência entre crítica literária e ensino de literatura pode ser observada a partir de três exemplos. O primeiro, o crítico brasileiro de maior repercussão social, Antonio Candido, empreendeu a significativa análise sobre os chamados "momentos decisivos" da literatura brasileira na obra Formação da literatura brasileira ${ }^{6}$ e, a seguir, discutiu o problema da representação literária partindo da "consciência do subdesenvolvimento" e das tendências particularistas e universalistas, utilizando-se metáforas orgânicas que vinculavam placentariamente nossa literatura às europeias. Uma segunda ilustração pode ser localizada nas considerações de Flora Süssekind que, em Tal Brasil, qual romance ${ }^{7}$, discute a presença constante da estética naturalista na literatura brasileira, lançando luzes sobre o tema da representação na nossa literatura e na nossa crítica, uma vez que, nessa estética, há uma equiparação entre ler e ver o texto que se afirmava como assimilação do real. Por último, o discurso crítico-marxista de Roberto Schwarz, que, explorando o deslocamento das ideias e a importação das formas, pretende rever os conceitos de nacionalidade e dependência cultural, principalmente quando problematiza o narrador machadiano, em Um mestre na periferia do capitalismo ${ }^{8}$.

Divergindo ou concordando com a direção que tais críticos fornecem, o fato é que eles oferecem marcas de reflexão intelectual sobre os modos de leitura e abrem caminhos para outras orientações, mesmo que lhes sejam antagônicas. Diante de tais exemplos, deparamo-nos com formas de apreensão de um tempo histórico-literário e de reflexões sistematizadas sobre obras e autores específicos, as quais, em graus variados, são assimiladas e difundidas pelo ensino da literatura. Assim encaminhada a questão, o exame do leitor e da leitura na contemporaneidade acarreta na observação da situação da crítica literária atual, uma época de recusa da totalidade, da continuidade histórica e da homogeneidade e que, não obstante tudo isso, lança a escola no centro da agitação cultural dos nossos dias.

Por isso, no plano das observações sobre leitor, leitura e contemporaneidade - o que abrange, como disse, a atualidade da crítica literária - o alvo é o enfrentamento sobre a finalidade do ensino da literatura. O leitor comum, não profissional, não abre um livro para dominar um método teórico ou sociológico. Se alguém lê decorridos os anos escolares é para encontrar questões e sentidos sobre o homem e o mundo e isso também se aprende na escola. Ler, em síntese, abrange

\footnotetext{
${ }^{6}$ CANDIDO, Antonio. Formação da literatura brasileira (momentos decisivos). Rio de Janeiro; Belo Horizonte: Itatiaia, 1987.

${ }^{7}$ SÜSSEKIND, Flora. Tal Brasil, qual romance?: uma ideologia estética e sua história. Rio de Janeiro: Achiamé, 1984. ${ }^{8}$ SCHWARZ, Roberto. Um mestre na periferia do capitalismo. Rio de Janeiro: Editora 34, 2000.
} 
experiências de vida e retoma a ideia de jogo, de lúdico e de subjetividade, dos quais, mesmo tendo que aferir a aquisição de conceitos fundamentais, nenhum professor pode prescindir.

Embora defenda enfaticamente a literatura como disciplina escolar e a repercussão funcional da crítica sobre a condução do seu ensino, reconheço que existem outros lugares de movimentação e experiências culturais por onde a literatura circula e se mostra objeto de enunciação. Refletir sobre eles é também responsabilidade do professor de literatura e, por seus sinais inquietantes, tarefa da crítica literária.

\section{Fenômenos contemporâneos de apreciação literária}

A presente discussão pode se tornar mais fecunda a partir da refuncionalização da literatura conforme compreendida por Silviano Santiago em "Literatura e cultura de massa". Analisando o texto de Walter Benjamin, "A obra de arte na época de sua reprodutibilidade técnica", Silviano Santiago desenvolve a seguinte perspectiva: há "refuncionalização da obra de arte operada pela transformação propiciada pelos meios de reprodutibilidade técnica"10. Essa refuncionalização se manifesta na perda de valor de culto de uma obra que, despida desse valor de culto, passa a ter uma "práxis social leiga".

A partir dessa perspectiva, é possível observar outro locus de disseminação da literatura para além da escola: o ciberespaço. Não são poucos os críticos e professores que resistem às observações e aos procedimentos circulantes no ambiente digital. Alegam superabundância de informações e perecibilidade imediata de modas efêmeras, atributos incompatíveis com o universo da leitura. Parece-nos difícil, observando esse panorama, concordar que as novas tecnologias de comunicação possam contribuir para formação consistente e significativa da literatura como prática cultural. Contudo, a apreciação e o consumo da literatura no meio digital são realidades crescentes. Blogs, vlogs e perfis de Facebook são exemplos que se somam ao mais recente fenômeno mundial dos Bookubers, uma forma de promoção de cultura compartilhada.

As questões que emergem dessas mídias e suas formas simbólicas se impõem progressivamente à medida que percebemos que a literatura se mantém como interesse para além do ambiente escolar. Para mim, literatura não tem finalidade salvífica. Por outro lado, ela nos ensina muito sobre a experiência humana, favorece a abstração, independentemente do grau de dificuldade de determinado texto. Por isso, assim como os estudos da leitura em perspectiva histórica remetem a circunstâncias de usos e costumes, na perspectiva contemporânea deve igualmente reconhecer os traços das práticas digitais no cerne das representações literárias e seus

\footnotetext{
9 Santiago, Silviano. "Literatura e cultura de massa." In: Novos Estudos CEBRAP, nº. 38, março, 1994, pp. 89-98.

${ }^{10}$ Ibidem, p. 94.
} 
suportes. Essa via permite um olhar plural para as categorias leitor, leitura e contemporaneidade e rompe com a ideia monolítica e homogênea que comumente se atribui ao processo de leitura; processo este de intensa complexidade e realizável em ambientes diversos, ainda que sua formalização ocorra na escola.

Esta reflexão é necessária para analisar o fenômeno dos Booktubers. Eles não são professores, nem críticos literários, nem os substituirão; possuem outra dicção porque se sustentam pelo apelo midiático dos meios de comunicação de massa e merecem um tratamento cuidadoso por parte da escola e da crítica literária na discussão sobre leitor e leitura na contemporaneidade. Primeiramente por ser uma forte tendência mundial; e, em segundo lugar, porque amplia o conceito e o valor da leitura. Examinando outros elementos, em seu novo livro, Mutações da literatura no século XXI, a professora e crítica literária Leyla Perrone-Moisés ${ }^{11}$ discute tanto autores que no passado fizeram profecias sobre o declínio da literatura, como os contemporâneos empenhados em provar que ela está viva. Em entrevista publicada em 30 de setembro de 2016 a respeito do assunto, ela afirmou o seguinte:

A verdadeira questão é a do público leitor atual. Não há mais grande público leitor, só a cultura audiovisual tem grande público. Nem por isso a prática da boa literatura terminou. ${ }^{12}$

Booktubers arrebatam, em geral, grande público, mas não ocupam o lugar da crítica porque são operações do texto literário completamente diferentes. Trata-se de pessoas individualmente ou grupo de pessoas que - como de praxe no YouTube - têm seus seguidores. Eles derivam dos blogs e simulam formas de diálogo. Se a crítica literária exige lento e contínuo processo, o Booktuber é imediatista e incide sobre a mídia de massa, notadamente o YouTube, plataforma de intermediação cultural que vem transformando a sociedade como um todo, inclusive a própria mídia. $\mathrm{O}$ YouTube envolve novas formas de narrar e de comunicar suas próprias experiências culturais, incluindo a literária. Uma forma crítica de se pensar, então, o fenômeno dos Booktubers não é a imediata e absoluta recusa, mas é tentando entender não somente o que ele propõe, mas como ele é assimilado e utilizado pelos usuários. Em outras palavras, entender o gosto particular compartilhado através do YouTube.

Os Booktubers, conforme caracterizou Tauana Jeffman ${ }^{13}$, possuem o seguinte formato: pertencem à "cultura de quarto", isto é, o lugar onde se realiza o vídeo é o da intimidade do Booktuber. Os chamados vlogs são imediatistas e requerem a reação dos usuários, construindo uma rede

\footnotetext{
${ }^{11}$ PERRONE-MOISÉS, Leyla. Mutações da literatura no século XXI. São Paulo: Companhia das Letras, 2016.

12 JEFFMAN, Tauana. "Literatura compartilhada: uma análise da cultura participativa, consumo e conexões nos Booktubers." In: Revista Brasileira de História da Mídia. V. 4, n. 2, 2015. Disponível em: http://ojs.ufpi.br/index.php/rbhm/article/view/4166/2477
} 
social. Eles instam os participantes a reagirem e a participarem, compartilhando os vídeos. Há Booktubers de todos os calibres, especializados ou não. As idades vão de 14 até 40 anos e tem por objetivo opinar sobre um livro e, muitas vezes, construir um fandom (domínio dos fãs). O fandom engloba diversas manifestações próprias do campo literário (produção, recepção etc) e gera novas formas de apreciação a partir do encontro de fãs. Um desdobramento do fandom é a fanfic (ficção de fã), que, na literatura brasileira, ainda está em processo de gestação, especialmente a partir da obra de Machado de Assis.

A crítica literária e a escola devem olhar mais atentamente para esses fenômenos não para os tomar como conceito-chave ou práticas absolutas. São fenômenos desafiadores que propiciam alguns desvios e muitas reflexões. Uma vez que caiba à escola formar pessoas com sólida cultura humanista e considerando que, hoje, grande parte da população possui acesso aos recursos tecnológicos, reconhecer as práticas de leitura distintivas e até imprevistas não significa a falência do ensino da literatura. Quanto à crítica, sua função mais interessante, ao meu ver, não é inibir contundente e indiscriminadamente todas as iniciativas contemporâneas, mas ler e fruir livros, avaliando-os e discutindo as referências que lhes dão suporte. A internet, por sua vez, traz novas formas de criação e de desfrute e, como vem transformando todas as práticas culturais, transforma também a escola e a literatura, redefinindo seus paradigmas. Não há hoje um só setor da vida humana que não esteja mediado e permeado pelas tecnologias digitais e este princípio operativo é assimilado à produção cultural da qual a literatura emerge.

Para melhor argumentar, gostaria de apontar três exemplos de relacionamento com os Booktubers que ilustram como um código de comunicação dentro do contexto global dos nossos dias pode ser ferramenta de promoção de leitura na era digital.

O Fondo Nacional de Cultura Económica do México promoveu o bem-sucedido concurso nacional de Booktubers com a finalidade de criação de vídeos-resenhas difundidas pelos meios culturais ${ }^{14}$. Na Argentina, o Ministério de Educação tem buscado difundir a leitura, fomentando concursos a partir de vídeos de curta duração (até 5 minutos) com opiniões sobre livros e participação em Feiras do Livro ${ }^{15}$. E no Chile, a mais bem sucedida experiência de institucionalização do fenômeno, a Dirección de Bibliotecas, Archivos y Museos (DIBAM) caminha para o terceiro concurso nacional de Booktubers e conta com a participação de mais de 450 bibliotecas $^{16}$.

Se a literatura pode enriquecer a vida e o pensamento, estimulando forças expressivas no leitor e se ela se imiscui de múltiplos canais de circulação, não seria bom para o ensino da literatura se onerássemos os

\footnotetext{
${ }^{14} \mathrm{https}: / / \mathrm{www}$. fondodeculturaeconomica.com/booktubers/convocatoria2016.pdf

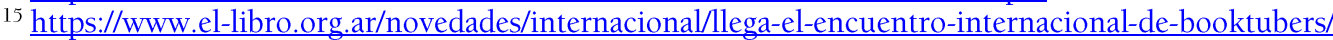

${ }^{16} \mathrm{http}: / /$ www.bibliotecaspublicas.cl/624/w3-article-78229.html
}

133 | D O S S I Ê : LEITORES E LEITURAS NA CONTEMPORANEIDADE 
jargões acadêmicos e enfrentássemos as questões com os envolvidos? Se a cultura digital delineia o mapa das práticas culturais contemporâneas, não é necessário olhar nesse traçado as formas de leitura produzidas nesse ambiente?

\section{Finalizando}

$\mathrm{Na}$ contemporaneidade, a questão da legitimidade do saber é colocada em outros termos. A crítica é uma atividade elaborada que não concorre com os fenômenos do ciberespaço. Há um movimento que se repete: leitura é prática histórica e cultural que absorve os processos de transformação social. Foi assim entre o romance e o jornal na ascensão do gênero, mas podemos nos lembrar dos impactos da fotografia, do rádio e de outros. Reforço que o tempo lento e isolado da leitura pressupõe uma aprendizagem que não abre mão dos bancos escolares. É na escola que se aprende formalmente a ser leitor. Contudo, é verdade também que a literatura não é exclusivamente matéria verbal e participa ativamente da cultura, cuja essência é uma continuidade em transformação. Literatura e cultura não existem num vácuo social, nem na esterilidade de comportamentos saudosistas. É na convergência de imaginários que a literatura se recria e, nesse âmbito, creio que a tônica do nosso tempo não prescinde da cultura digital.

No ambiente dos Booktubers, obras de Fernando Pessoa ou de Clarice Lispector são partilhadas, integral ou parcialmente, com o mesmo despojamento com que se fala de qualquer outro assunto. Há professores de literatura envolvidos na construção desses vlogs e leitores comuns, profissionais de outras áreas. Além de discutirem obras, que geram centenas de comentários, são lançadas questões, tais como: "quem pode falar de literatura?"; "existe diferença entre apreciação literária e crítica literária?"; "quem sabe mais sobre um livro: quem leu um livro ou quem leu sobre o livro (artigos, resenhas etc.)?". Alguns misturam emoções, impressões, outros comentam aspectos da técnica narrativa empregada. Seja como for, a tecnologia digital tem se tornado popular e acessível a uma vasta camada da população mundial. Devido às facilidades proporcionadas por esse tipo de tecnologia para produção, distribuição e consumo de informação, a cultura contemporânea está se tornando cada vez mais atrelada ao computador (em seus vários e cambiantes formatos), bem como a inúmeros aparelhos móveis, o que tem levado alguns pensadores a postularem o termo "cultura digital" para pensar a contemporaneidade. Dentro desse contexto, vêm ocorrendo diversas transformações e deslocamentos nas experiências de produção, leitura, escrita e formação de leitor e leitura literária, tais como o surgimento da literatura eletrônica (ou digital), os aplicativos literários para adultos, jovens e crianças, os blogs e sites literários, as comunidades de fanfiction, 
dentre outros.

Por fim, uma pequena palavra sobre a apropriação da internet no ensino da literatura e reflexões sobre leitura. De antemão, aponto dois riscos e alguns ganhos. O primeiro risco é fazer dessa experiência a única possível a partir de agora, negligenciando o silêncio, o isolamento, que são imprescindíveis ao ato de ler e deixando de lado a tradição como objeto de conhecimento. Os fenômenos do ciberespaço são suportes não totalizantes, são experiências referentes à contemporaneidade, que podem bem se somar a um ângulo de análise ou ser problematizadas em sala de aula. O segundo risco é inundar o ensino da literatura de fenômenos paraliterários, limitando-o ao simpático, ao fácil e ao popular.

Por outro lado, os ganhos são muitos. O principal e mais convincente deles é a análise de um corpus complexo produzido pela contemporaneidade e a compreensão das práticas culturais do tempo presente, o que pode conduzir leitores jovens em fase de formação a uma perspectiva crítica, que os permita discernir seus objetos e meios de consumo. Seria muito nocivo ignorarmos as categorias contemporâneas, assim como é ruim desconhecermos os conceitos e as obras produzidas pela tradição. No ensino da literatura, espera-se que o professor seja capaz de problematizar as tensões históricas e culturais de certa época pretérita e este exame também se emprega ao tempo presente. Se se aprende a ler na escola, nessa aprendizagem penetram os códigos de suporte da leitura. Por isso, uma série de interrogações emergem da análise sobre o leitor e a leitura na contemporaneidade. Todavia, não trago, nem tenho respostas prontas, nem quero apresentar nesse espaço receitas, menos ainda teorias mirabolantes. Espero apenas chamar a atenção para o ensino da literatura e para a crítica literária como canais de exame de certas práticas atuais de apreciação literária. 